\title{
Quinoline-resistance reversing agents for the malaria parasite Plasmodium falciparum
}

\author{
Donelly A. van Schalkwyk ${ }^{a, * *}$, Timothy J. Egan ${ }^{\mathrm{b}, *}$ \\ a School of Biochemistry and Molecular Biology, Faculty of Science, The Australian National University, \\ Canberra ACT 0200, Australia \\ ${ }^{\mathrm{b}}$ Department of Chemistry, University of Cape Town, Private Bag, Rondebosch 7701, South Africa
}

\begin{abstract}
Resistance to quinoline antimalarials, especially to chloroquine and mefloquine has had a major impact on the treatment of malaria worldwide. In the period since 2000, significant progress has been made in understanding the origins of chloroquine resistance and to a lesser extent mefloquine resistance in Plasmodium falciparum. Chloroquine resistance correlates directly with mutations in the pfcrt gene of the parasite, while changes in another gene, pfmdrl, may also be related to chloroquine resistance in some strains. Mutations in $p f c r t$ do not appear to correlate with mefloquine resistance, but some studies have implicated $p f m d r l$ in mefloquine resistance. Its involvement however, has not been definitively demonstrated. The protein products of these genes, PfCRT and Pgh-1 are both located in the food vacuole membrane of the parasite. Current evidence suggests that PfCRT is probably a transporter protein. Chloroquine appears to exit the food vacuole via this transporter in resistant PfCRT mutants. Pgh-1 on the other hand, resembles mammalian multi-drug resistance proteins and appears to be involved in expelling hydrophobic drugs from the food vacuole. Resistance reversing agents are believed to act by inhibiting these proteins. The currently known chloroquine- and mefloquine-resistance reversing agents are discussed in this review. This includes a discussion of structure-activity relationships in these compounds and hypotheses on their possible mechanisms of action. The status of current clinical applications is also briefly discussed.
\end{abstract}

(C) 2006 Elsevier Ltd. All rights reserved.

Keywords: Malaria; Chloroquine; Mefloquine; Quinine; Resistance reversers

\section{Introduction}

Malaria is a leading cause of morbidity and mortality worldwide (WHO Expert Committee on Malaria, 2000). It also plays a major role in underdevelopment in tropical countries, especially in Africa (Sachs and Malaney, 2002). The appearance and spread of drug-resistant strains and especially of chloroquine-resistant (CQR) strains of Plasmodium falciparum has had disastrous consequences in many of the World's poorest countries (WHO Expert Committee on Malaria, 2000). Affordable alternatives are often not available for these countries. In addition, the efficacy of alternative drugs such as quinine $(\mathrm{QN})$ has been noticeably reduced in

\footnotetext{
* Corresponding author. Tel.: +27 21650 2528; fax: +27 216897499 .

** Corresponding author. Tel.: +61 26125 9776; fax: +61 261250313 .

E-mail addresses: don.vanschalkwyk@ anu.edu.au

(D.A. van Schalkwyk), tegan@ science.uct.ac.za (T.J. Egan).
}

some regions, while full-scale resistance to other drugs such as mefloquine (MQ) and the antifolates has also appeared. Following the discovery that the calcium channel-blocker verapamil (VPL) restores chloroquine-sensitivity (CQS) in CQR strains (Krogstad et al., 1987; Martin et al., 1987), there has been considerable interest in such so-called resistancereversing agents. MQ-resistance (MQR) reversers have also subsequently been identified.

The mechanism of action of quinoline antimalarials remains to be definitively demonstrated. Current evidence strongly suggests that CQ accumulates in the digestive food vacuole of the malaria parasite. This occurs as a result of $\mathrm{pH}$ trapping of the basic CQ molecule in the acidic food vacuole and possibly also as a result of association of CQ with haem in the food vacuole. There CQ is believed to interfere with haem accumulation into haemozoin resulting in the parasite being subjected to haem toxicity, leading to its death. This hypothesis has been reviewed recently in a number of 
publications and will not be discussed further here (Ziegler et al., 2001; Sullivan, 2002; Egan, 2003; Egan, 2004).

This review will discuss the current state of knowledge about the mechanism of action and structure-activity relationships in antimalarial drug resistance-reversing agents.

\section{Resistance to quinolines}

\subsection{Chloroquine resistance}

The issue of chloroquine resistance (also abbreviated CQR) can be approached by addressing three different, but interrelated, questions. Firstly, what are the changes to the cell physiology of the parasite that cause CQR? Secondly, what genetic mutations in the parasite give rise to CQR and what are the protein products of these genes? Thirdly, what relationships exist between the structures of CQ analogues and cross-resistance with CQ? The first question is still the subject of inquiry and vigorous debate. Considerable progress has been made on the second question since 2000. On the third question there is substantial empirical evidence. These issues will be briefly discussed in turn.

\subsection{The physiological basis of chloroquine-resistance}

In general, resistance to a drug can be brought about in several ways. Firstly the drug may be altered to become less active and thus less toxic to the cell concerned. Secondly the drug target may be altered so that the drug cannot exert its effect on the modified target. Thirdly the target may be overexpressed thereby reducing the effect of the toxin. Fourthly the drug may be denied access to its target by either a reduction in its accumulation or an increase in its efflux out of the cell or just away from its site of action. Current evidence strongly suggests that the last mechanism operates in the case of CQR.

Fitch was the first to report that CQR P. falciparum strains accumulate less CQ than do CQS strains (Fitch, 1969). This reduced accumulation of $\mathrm{CQ}$ forms the basis for all hypotheses of resistance to CQ. The manner in which this is achieved though has been widely debated and remains unresolved. Another distinctive characteristic of resistance to CQ is the ability to reverse its resistance using agents like VPL. However, some recently discovered strains appear to lack this characteristic as will be described later.

One proposal for the mechanism of CQR is that resistant strains efflux CQ more rapidly than sensitive strains. Such behaviour was first proposed by Krogstad et al. in 1987. CQ was reported to be effluxed from CQR strains at a rate 40-50 times faster than that seen in a CQS strain. Others have subsequently reported a similar finding (Bayoumi et al., 1994). The efflux mechanism has been claimed to be energy dependant, as it is significantly less effective in the absence of glucose (Krogstad et al., 1992). More recently, it was once again asserted that the efflux mechanism is responsible for reduced accumulation and that this was an energy dependent process
(Sanchez et al., 2003; Sanchez et al., 2004; Sanchez et al., 2005). However, two groups have questioned these hypotheses. Firstly Bray et al. showed that both CQS and CQR strains have similar efflux rates with the CQS strain showing a marginally faster rate of efflux (Bray et al., 1992a). They proposed that a reduced accumulation mechanism would better explain the differences between CQS and CQR strains. This was supported by Martiney et al. who also could not distinguish between the efflux rates of CQS and CQR strains (Martiney et al., 1995). The status of the CQ-efflux proposal thus remains unresolved.

An alternative to an efflux mechanism is a decrease in CQ uptake into the digestive vacuole. The simplest hypothesis that could account for decreased uptake of CQ in CQR parasites is an increase in digestive vacuole $\mathrm{pH}$ and some early evidence suggested that CQR parasites indeed exhibit increased digestive vacuole $\mathrm{pH}$ (Krogstad et al., 1985). Since $\mathrm{CQ}$ accumulation is at least in part a result of the $\mathrm{pH}$ gradient between the parasite cytoplasm and the digestive vacuole, any reduction in this gradient would lead to less CQ being taken up by the parasites. Increased digestive vacuole $\mathrm{pH}$ was attributed to a weakened digestive vacuole proton pump and was based on evidence from kinetic modelling (Ginsburg and Stein, 1991) and the use of $\mathrm{pH}$ altering agents (Bray et al., 1992b). However, there is no definitive evidence supporting this hypothesis.

More recently, using single cell-level analysis of digestive vacuole $\mathrm{pH}$, Dzekunov et al. provided evidence that the CQR Dd2 strain actually has a lower $\mathrm{pH}$ than the CQS HB3 strain (Dzekunov et al., 2000). Using the fluorescence intensity of acridine orange in the digestive vacuole to quantify the absorption of the weak base and thus the $\mathrm{pH}$, they calculated the $\mathrm{pH}$ of the CQS strain at 5.64. Their CQR strain had a pH of 5.21. Anomalously, this evidence would suggest increased $\mathrm{CQ}$ accumulation in the digestive vacuole of the CQR strain. To explain this apparent contradiction, Ursos et al. proposed that the lower $\mathrm{pH}$ in the $\mathrm{CQR}$ parasites reduces the amount of free haem since the availability of soluble haem is highly $\mathrm{pH}$ dependent (Ursos et al., 2000). Since CQ accumulation has been proposed to be determined by its access to free haem (Bray et al., 1998), the CQR parasites would then be expected to accumulate less $\mathrm{CQ}$ at this lower $\mathrm{pH}$. The interpretation of the experimental evidence was later questioned by Bray et al. (2002). They suggested that the acridine orange fluorescence measured was not in fact digestive vacuole fluorescence but rather that it was cytosolic. They also argued that any fluorescence in the digestive vacuole as a result of acridine orange would, to a large degree, be quenched by the haem. Subsequent studies have tried to iron out these experimental questions (Waller et al., 2003). However, this hypothesis for explaining the resistance to CQ remains highly controversial (Kirk and Saliba, 2001). Furthermore a recent study by Hayward et al. used a range of dextran-linked $\mathrm{pH}$-sensitive dyes to demonstrate that there was no significant difference between the $\mathrm{pH}$ of the digestive vacuole between CQS and CQR strains (Hayward et al., 2006). 
A major weakness of hypotheses that posit a general change in digestive vacuole $\mathrm{pH}$ is that it would be expected to cause cross-resistance to a range of quinoline-like antimalarials that also accumulate by means of $\mathrm{pH}$ trapping and/or their interaction with haem in the digestive vacuole and this is manifestly not the case. For example, CQ analogues with shorter or longer side-chains are equally effective against both CQR and CQS strains (De et al., 1996; Ridley et al., 1996). These analogues should accumulate similarly to CQ and thus a change in $\mathrm{pH}$ should also induce cross-resistance to these compounds. The structural specificity of CQ resistance suggests a specific transporter-mediated mechanism is involved (Ridley and Hudson, 1998).

\subsection{The genetic basis of $C Q R$ and corresponding proteins}

Several genes have been implicated in resistance to CQ in P. falciparum. Originally because of the apparent similarities between CQR in P. falciparum and multi-drug resistance (MDR) in cancer cells and the chemosensitization in both instances by VPL (Rogan et al., 1984; Martin et al., 1987), it was thought that a homologue of the human P-glycoprotein (Pgp) responsible for drug-resistance in cancer cells was involved.

Two genes encoding P-glycoprotein homologues have been discovered in P. falciparum; pfmdrl and pfmdr2 (Foote et al., 1989; Wilson et al., 1989). The protein product of pfmdrl, P-glycoprotein homologue 1 (Pgh-1), is a $160 \mathrm{kDa}$ protein located primarily on the digestive vacuole of the parasite (Cowman et al., 1991). Pgh-1 expression levels are not always associated with CQR since equal amounts have been detected in both the CQS and CQR strains tested (Cowman et al., 1991). In a separate study, several progeny from a genetic cross between the CQS HB3 and CQR Dd2 strains were compared in their sensitivity to $\mathrm{CQ}$ and $\mathrm{MQ}$, their $\mathrm{CQ}$ efflux halftimes, pfmdrl copy number and restriction fragment length polymorphism (RFLPs). No linkage could be found between the CQR phenotype and the pfmdrl gene (Wellems et al., 1990). It was later demonstrated that highlevel CQR was incompatible with increased Pgh-1 expression (Barnes et al., 1992). CQ pressure on FAC8, a strain expressing three copies of Pgh-1, caused a de-amplification of the pfmdrl gene and loss of Pgh-1 expression. Also no amino acid change was seen in Pgh-1. However, cells deficient in Pgh-1 become more sensitive to MQ. Thus, pfmdrl copy number may be linked to MQ resistance (Barnes et al., 1992). However, when MQ was used to pressure this strain (FAC8), the new highly mefloquine resistant lines were found to have no further increase in Pgh-1 expression (Lim et al., 1996). Also there were no changes in amino acid composition of pfmdrl. Thus, mutations or changes in amplification or expression of pfmdrl are not essential in either CQ resistance or increased resistance to MQ. Nonetheless, Reed et al. demonstrated that Pgh-1 can modulate sensitivity of Plasmodium to several antimalarials (Reed et al., 2000). Although mutations in Pgh-1 cannot confer CQ resistance alone, they can lead to increased CQ resistance through decreased drug accumulation. This increase in resistance is susceptible to VPL. Thus, Pgh-1 mutations do appear to have a role in modulation of CQR in at least some strains of P. falciparum (Reed et al., 2000). The $p f m d r 2$ gene and its protein product do not seem to be involved in resistance to CQ in P. falciparum (Wilson et al., 1989; Wellems et al., 1990; Rubio and Cowman, 1994).

In 1997, Su et al. identified two genes with complex polymorphisms that were closely linked to CQR P. falciparum. These two genes were called $c g 1$ and $c g 2$. Later however, Fidock et al. were able to demonstrate that $c g l$ and $c g 2$ do not alter the response of $P$. falciparum parasites to CQ (Fidock et al., 2000a). They used DNA transfection and allelic exchange to replace the polymorphisms in either $c g 1$ or $c g 2$ from CQR strains with those of the CQS HB3 strain. All the CQR strains remained resistant to CQ and all maintained their verapamil reversibility irrespective of substitutions in either the $\mathrm{cgl}$ or $c g 2$ genes. However, the close association between the polymorphisms within these genes and the CQR strains suggested that a gene nearby might be responsible for the CQR phenotype. This then led to the identification of Plasmodium falciparum chloroquine resistance transporter (PfCRT) (Fidock et al., 2000b).

PfCRT is a $48.6 \mathrm{kDa}$ protein containing 10 transmembrane domains but lacking an ATP-binding motif. It has been localized to the digestive vacuole membrane of the parasite using western blotting and immunomicroscopy techniques (Fidock et al., 2000b). The normal function of PfCRT remains unknown, but disruption of the pfcrt gene has been found to be deleterious to parasite viability indicating that PfCRT is important in maintaining parasite growth (Waller et al., 2003). CQR strains with mutations in PfCRT at position 76 (K76T or K76I) linked with resistance to CQ have been reported to be associated with an increased digestive vacuole acidification (Waller et al., 2003). Another mutation strongly associated with CQR involves a change of an asparagine to a serine (A220S), although this mutation does not confer CQR in the absence of the K76T mutation. It is notable that while decreased QN sensitivity is associated with PfCRT mutations, changes in $p f c r t$ expression have little effect on parasite sensitivity to QN and MQ (Waller et al., 2003). Initially it seemed that PfCRT mutations were not linked to MQ resistance and had been shown to increase the sensitivity to MQ (Cooper et al., 2002; Sidhu et al., 2002). However, the halofantrineresistance selected line (K1HF) demonstrated a decreased sensitivity to MQ suggesting that PfCRT mutations may also play a role in MQ-resistance (Johnson et al., 2004).

The mutation in PfCRT that appears to be most important in determining the CQR phenotype involves the change of a charged amino acid, lysine, to an uncharged amino acid, threonine (K76T). Other mutations also involve changes in charge from lysine to asparagine $(\mathrm{K} 76 \mathrm{~N})$ or lysine to isoleucine (K76I). These mutations all suggest that a specific protein target is involved in resistance to CQ as well as its reversal by chemosensitisers (Cooper et al., 2002). 
Using $p$ fcrt-modified "knockdown" clones, Waller et al. were able to decrease $p f c r t$ transcription levels and PfCRT protein expression levels (Waller et al., 2003). This resulted in a drop in $\mathrm{CQ} \mathrm{IC}_{50}$ relative to the $7 \mathrm{G} 8$ parent line. These knockdown clones are also reported to have an altered digestive vacuole $\mathrm{pH}$ similar to that found in CQS lines (Waller et al., 2003). This suggests a possible link between expression of PfCRT, sensitivity to CQ and altered digestive vacuole $\mathrm{pH}$ in P. falciparum.

There can now be little doubt that mutations in PfCRT are directly linked to $\mathrm{CQR}$ in laboratory strains and they have also been reported in field isolates (Fidock et al., 2000b; Chen et al., 2003; Nagesha et al., 2003; Durrand et al., 2004). Nonetheless, as pointed out in a recent review by Cooper et al., resistance probably entails a complex spectrum of genes, some of which may not be directly responsible for resistance, but nonetheless may be vital to ensure viability of resistant parasites by compensating for losses in function that may be directly related to CQR (Cooper et al., 2005).

By selecting for the in vitro resistance to amantadine or halofantrine, Johnson et al. were able to sensitize CQR parasites to CQ while still maintaining the K76T mutation in PfCRT (Johnson et al., 2004). They demonstrated that unique mutations in PfCRT, especially S163R, could induce resistance to other antimalarials. There have been reports of CQR field isolates that lack the K76T mutation (Thomas et al., 2002; Lim et al., 2003) and also some evidence has been reported of patients harbouring parasites with the K76T mutation that nonetheless respond to CQ treatment (Chen et al., 2002; Happi et al., 2003). This may indicate that other proteins, including Pgh-1 (Reed et al., 2000), as well as patient immunity may also play a role in clinical failure of CQ.

CQ has recently been demonstrated to bind directly to PfCRT (Zhang et al., 2004). However, no strong evidence has been shown that quinine is also bound, although PfCRT is able to modulate quinine resistance. Through comparing the sequence of PfCRT with other 10 transmembrane transporter sequences, Tran and Saier found significant homology with a nucleotide sugar transporter of the drug/metabolite transporter (DMT) superfamily (Tran and Saier, 2004). They suggested that PfCRT functions as a transporter. This has also been investigated by Martin and Kirk, who also found homology with the DMT superfamily (Martin and Kirk, 2004). PfCRT was predicted to function as a dimer, acting as an efflux transporter with the critical K76 residue orientated towards the digestive vacuole lumen. These authors suggested that mutation of this amino acid to a neutral residue permits efflux of the cationic protonated CQ molecule. This supports an earlier suggestion by Warhurst who has provided evidence that the ability of compounds to be extruded through PfCRT decreases in proportion to their lipophilicity (Warhurst et al., 2003a; Warhurst, 2003b). Furthermore, VPL is proposed to bind to PfCRT and prevent CQ extrusion on account of its positively charged protonated amino group which compensates for the lost lysine residue.
Interestingly, two recent papers have reported unique mutations in $\mathrm{CQR}$ strains from South America, Papua New Guinea (C72S/K76T) and the Philippines (K76T/A144T/L160Y/N326D) that are associated with a reduction of VPL reversibility of CQR (Mehlotra et al., 2001; Chen et al., 2003). Resistance to CQ is assumed to have developed independently from different geographical foci which are broadly classified as the Asian/African Dd2 type (VPL-reversible) and the South American/Oceanic 7G8 (VPL-insensitive) types. Both the CQR phenotypes are reported to exhibit a reduced digestive vacuole $\mathrm{pH}$ relative to the CQS strains (Mehlotra et al., 2001; Chen et al., 2003). In the presence of VPL the Dd2 type parasites are reported to experience an increase in digestive vacuole $\mathrm{pH}$ (alkalinized) whereas the 7G8 type shows no change in digestive vacuole $\mathrm{pH}$ when exposed to $5 \mu \mathrm{M}$ VPL (Bennett et al., 2004).

$\mathrm{CQR}$ in Plasmodia other than P. falciparum has not been shown to be linked to $p f c r t$ or $p f m d r l$ (Li et al., 1993; Carlton et al., 1998; Hunt et al., 2004). Homologous genes to both pfcrt (PvCG10) and pfmdr1 (PvMDR1) have been reported in Plasmodium vivax strains but neither genes demonstrate any mutations associated with chloroquine resistance in these strains (Nomura et al., 2001; Sa et al., 2005). Thus, the genetic basis of resistance to chloroquine in $P$. vivax has yet to be elucidated.

\subsection{Relationship between quinoline structure and cross-resistance with $C Q$}

A number of CQ analogues have been shown to be active against CQR P. falciparum (Fig. 1). Amodiaquine (AQ) exhibits activity against many strains of CQR parasites and is still used clinically, although cross-resistance with some strains is significant (Bray et al., 1996). CQ analogues with shortened and lengthened aminoalkyl side-chains have been shown to exhibit undiminished activity against CQR parasites (De et al., 1996). Other CQ analogues with modified side chains, including shortened side-chains (Ridley et al., 1996), ferrocene containing side chains (ferroquine, FQ, and related compounds) (Biot et al., 1997) and gold complexes of CQ (Navarro et al., 1997) all show full activity against $\mathrm{CQR}$ parasites. Some of these compounds are currently in clinical development, including isoquine (an AQ analogue) and FQ (O'Neill et al., 2003; Biot et al., 2004). These data suggest that the side chain is a primary recognition motif for CQR, although there is some evidence that the 4-amino7-chloroquinoline ring itself may be weakly correlated with cross-resistance with CQ (Madrid et al., 2005). These data appear to support the idea that specific binding of drugs to PfCRT, mainly through the side chain, lies at the basis of resistance. However, in many cases the active drugs are also considerably more lipophilic than CQ, so a relationship with increasing lipophilicity could be an additional factor, although this is not the case for the short side-chain analogues, which are all less lipophilic than CQ. 
<smiles>CCN(CC)CCNc1ccnc2cc(Cl)ccc12</smiles>

a<smiles>CCN(CC)CC(C)Nc1ccnc2cc(Cl)ccc12</smiles>

b<smiles>CCN(CC)CCCNc1ccnc2cc(Cl)ccc12</smiles>

c<smiles>CCN(CC)CCCCCCCCCCCCNc1ccnc2cc(Cl)ccc12</smiles><smiles>CCN(CC)Cc1ccc(Nc2ccnc3cc(Cl)ccc23)cc1O</smiles>

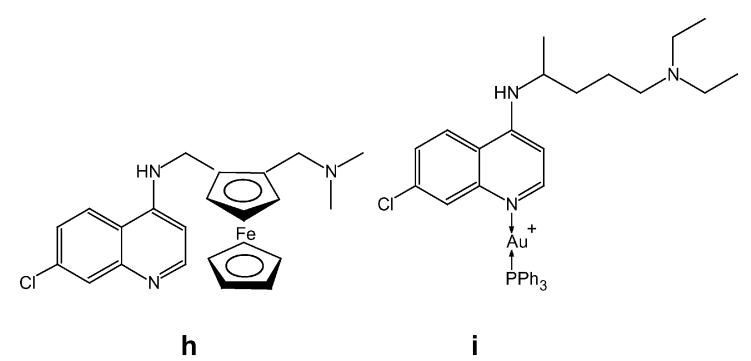

Fig. 1. A selection of CQ analogues that are active against CQR parasites, including short and long chain analogues (a-d), analogues with side chains containing bulky groups or aromatic rings (e-h) and metallated analogues (i). Among the compounds shown are AQ (f), isoquine (g) and FQ (h).

\section{Chloroquine-resistance reversers}

The phenomenon of CQ-resistance reversal in Plasmodium falciparum is characterized by both a reduction of the CQ $\mathrm{IC}_{50}$ and the increased accumulation of CQ into CQR strains specifically (Krogstad et al., 1987; Martin et al., 1987). While CQ-resistance reversers are able to decrease the parasite sensitivity to CQ to within levels associated with CQS strains, the increased accumulation of CQ in the presence of resistance reversers never reaches levels found for CQS strains. Thus, unlike multidrug-resistance reversal in cancer cells, these agents induce only a partial reversal of the CQR phenotype in Plasmodium falciparum.

As mentioned above, VPL was the first compound demonstrated to reverse chloroquine resistance (Krogstad et al., 1987; Martin et al., 1987). It is a monoprotic weak base that is known to block L-type calcium channels in smooth and cardiac muscle (Fleckenstein et al., 1967). The action of VPL in malaria as a chemosensitizer has been demonstrated to be independent of calcium channels (Ye and Van Dyke, 1988). Whereas calcium channels are specifically blocked only by the (S)- $(-)$ isomer, the resistance reversal activity in malaria can be achieved by both the (R)-(+) and the (S)-(-) isomer (Ye and Van Dyke, 1988). Also VPL does not decrease the levels of free calcium within the parasites at concentrations that inhibit parasite growth $(10-20 \mu \mathrm{M})$ (Adovelande et al., 1993). This suggests that calcium movement into the parasite or the digestive vacuole does not depend on VPL-sensitive calcium channels (Adovelande et al., 1993). This behaviour mimics the role of VPL in reversing multidrug resistance in cancer cells, where it has also been demonstrated that VPL does not alter calcium levels in cells when it reverses resistance to antitumour agents (Cano-Gauci and Riordan, 1987).

VPL is able to enhance the action of CQ in CQR strains but has no effect on CQS strains (Martin et al., 1987). VPL is also able to modulate the parasite sensitivity to QN and that of it stereoisomer quinidine (Cooper et al., 2002; Waller et al., 2003). In plasmodial strains carrying the K76T or the K76N mutation in PfCRT, VPL has been shown to decrease the $\mathrm{IC}_{50}$ of $\mathrm{QN}$ to levels seen in the QN-sensitive strains. In the $P$. falciparum strain with a K76I mutation, a strain that exhibits hypersensitivity to QN, VPL increases the $\mathrm{IC}_{50}$ five fold (Cooper et al., 2002). This effect appears to be stereospecific, since decreased quinidine sensitivity remains VPL-reversible in the all strains carrying mutations at position 76 of PfCRT (Cooper et al., 2002). VPL however, has no effect on modulating MQ activity in strains that are MQR (Peters and Robinson, 1991; Oduola et al., 1993).

Early work showed VPL has a CQ-resistance reversal effect at concentrations that are non-toxic to the parasites (Martin et al., 1987). Toxic concentrations of VPL are usually 100-1000 times higher than those of CQ (Martin et al., 1987; Jacobs et al., 1988) and most CQR strains have a VPL reversible component.

VPL and other calcium channel blockers as well as certain phenothiazines shown to be resistance reversers have recently been shown to exhibit antimalarial activity in a concentration range similar to CQ in newly identified South American CQR strains and lack the ability to potentiate CQ action (Menezes et al., 2002; Menezes et al., 2003). The reason for this uncharacteristic response to chemosensitization is unknown but may be linked to mutations in PfCRT (Mehlotra et al., 2001).

The sensitivity of P. falciparum parasites to VPL has been linked to mutations in $p f m d r l$ (Hayward et al., 2005) and $p f c r t$ (Fidock et al., 2000b; Lakshmanan et al., 2005). Mutations in pfmdrl associated with resistance to MQ are also associated with decreased sensitivity to VPL (Hayward et al., 2005). In addition, parasites transformed with mutant $p f c r t$ were found to exhibit an increased sensitivity to VPL (Fidock et al., 2000b). 
The effect of VPL on the $\mathrm{pH}$ of the digestive vacuole of $P$. falciparum has also recently been described (Ursos et al., 2000). CQS parasites are reported to have a higher digestive vacuole $\mathrm{pH}$ than CQR parasites (Dzekunov et al., 2000). When VPL (either $1 \mu \mathrm{M}$ or $5 \mu \mathrm{M}$ ) was added to CQS parasites there was reported to be no effect on changing the vacuole $\mathrm{pH}$. However, when VPL was added to CQR parasites a 0.26 and $0.35 \mathrm{pH}$ unit increase at $1 \mu \mathrm{M}$ and $5 \mu \mathrm{M}$, respectively, was described (Ursos et al., 2000). These values approached the $\mathrm{pH}$ values for the CQS strain in the absence of VPL but never quite reached the same levels. This "renormalization" of the $\mathrm{pH}$ in $\mathrm{CQR}$ strains to that of CQS strains was proposed to occur through the effect of VPL on some as yet unknown ion transporter (Ursos et al., 2000). However, as stated earlier, these $\mathrm{pH}$ studies have been highly controversial and recent evidence has suggested that there is no difference in the digestive vacuole $\mathrm{pH}$ between CQR and CQS strains (Bray et al., 2002; Hayward et al., 2006).

Subsequent to the discovery of the chemosensitizing potential of VPL, a wide range of structurally and functionally diverse agents has been described that also demonstrate the ability to reverse CQ resistance (Figs. 2 and 3). Other calcium channel inhibitors were shown to reverse CQR in vitro (Ye and Van Dyke, 1988; Adovelande et al., 1998) and in vivo (Tanabe et al., 1990). Reversal of CQR has also been shown with tricyclic antidepressants both in vitro (Gerena et al., 1992; Taylor et al., 2000; Bhattacharjee et al., 2001) and in vivo in mice (Miki et al., 1992) and Aotus monkeys (Bitonti et al., 1988). Antihistamines are of greatest interest clinically because they are commonly co-prescribed with $\mathrm{CQ}$ to treat itching. Several studies using antihistamines show great promise in potentially restoring CQ efficacy in humans (Abok, 1997; Sowunmi and Oduola, 1997; Oduola et al., 1998). The diversity of structure and function of these resistance reversers has also been extended to the antipsychotic phenothiazines (Kyle et al., 1993; Singh and Puri, 2000; Van Schalkwyk et al., 2001; Kalkanidis et al., 2002), dibenzylsuberanylpiperazine derivatives (Osa et al., 2003) and even plant derived compounds (Haruki et al., 2000). Recently primaquine, an antimalarial with very limited blood-stage activity but used in treating the liver stage of $P$. vivax has been shown to reverse resistance (Bray et al., 2005).

At first sight the many functionally and structurally different compounds that are able to reverse $\mathrm{CQR}$ in $P$. falciparum appear somewhat bewildering. Upon closer inspection however, there appear to be certain specific characteristics that may be important in chemosensitization. For example most share the following characteristics: a cationic charge at digestive vacuole $\mathrm{pH}$, two planar rings, significant lipophilicity and a nitrogen atom, often tertiary (Gerena et al., 1992). The importance of charge at this proximal amine group can also be illustrated through the ineffectiveness of loratadine (Peters et al., 1990; Singh and Puri, 2000). Loratadine, an antihistamine, is structurally very closely related to azatadine, cyproheptadine and pizotyline, but has the $\mathrm{N}$ atom as part of a non-basic carbamate group instead of a basic amine group. Yet it has no effect either in vitro on P. falciparum (Peters et al., 1990) or in vivo on P. yoelii (Peters et al., 1990; Singh and Puri, 2000). Certain compounds that are highly effective at reversing resistance in MDR cancer cells (cyclosporin A, ivermectin, progesterone) have no effect on reversing CQR in P. falciparum (Van Schalkwyk et al., 2001). This supports the hypothesis that specific structural features are important for CQR reversal given that the three inactive examples lack some or all of the characteristics listed above yet are highly effective inhibitors of the mammalian P-glycoprotein (Zacherl et al., 1994; Pouliot et al., 1997).

Until recently little was known about structure activity relationships (SARs) in resistance reversing agents. However, in the last 5 years several articles have been published on SARs in these compounds (Bhattacharjee et al., 2001; Alibert et al., 2002; Bhattacharjee et al., 2002; Guan et al., 2002). A recent study on PfCRT mutants using allelic exchange also throws considerable light on the relationship between resistance reversal activity and PfCRT structure (Lakshmanan et al., 2005). Taken together, these studies provide considerable insight into the requirements for CQR reversal, its relationship to the mechanism of CQR and possible characteristics of the putative site of interaction of both resistance reversers and CQ with PfCRT.

In 2002 Bhattacharjee et al. conducted a 3D QSAR study of 17 imipramine analogues. These revealed a common pharmacophore which could also account for the activity of a number of unrelated CQR reversers. The basic features revealed for a resistance reverser are two hydrophobic aromatic rings and a hydrogen bond acceptor, preferably nitrogen. Substitution of the heterocyclic 7-membered ring in the imipramines was found to be required at N5 and a two or three carbon bridge to the $\mathrm{N}$ atom is optimal for activity. A tertiary or secondary $\mathrm{N}$ atom was found to be optimal. Nitrogen basicity, frontier orbital energies and lipophilicity were found to correlate with resistance reversing activity. Interestingly, comparison of all but two of the classes of

\footnotetext{
Fig. 2. Calcium channel blockers, dibenzazepines, phenothiazines and dihydroanthracenes reported to reverse CQR. In the case of the last three groups, where the compounds are known drugs their primary pharmacological application is indicated. The compounds are (a) verapamil (Krogstad et al., 1987; Martin et al., 1987), (b) devapamil (Ye and Van Dyke, 1988), (c) gallopamil (Ye and Van Dyke, 1988), (d) fantofarone (Adovelande et al., 1998), (e) diltiazem (Kyle et al., 1990), (f) nifedipine (Martin et al., 1987), (g) amlodipine (Basco and Le Bras, 1991), (h) nicardipine (Miki et al., 1992), (i) imipramine (Miki et al., 1992), (j) desipramine (Bitonti et al., 1988), (k) amitryptiline (Taylor et al., 2000), (l) cyproheptidine (Peters et al., 1990), (m) azatadine (Peters et al., 1990), (n) pizotyline (Peters et al., 1990), (o) ketotifen (Peters et al., 1990), (p) chlorpromazine (Kyle et al., 1990), (q) trifluoperazine (Miki et al., 1992), (r) promethazine (Oduola et al., 1998), (s) oxaprotiline (Taylor et al., 2000) and a series of novel dihydroanthracene derivatives (t-w) synthesised to probe CQR resistance reversal SARs (Alibert et al., 2002). Verapamil (a), diltiazem (e) and chlorpromazine (p) are also reported to reverse quinine resistance.
} 
<smiles>COc1ccc(CCN(C)CCCC(C)(c2ccc(OC)c(OC)c2)C(C)C)cc1OC</smiles>

a<smiles>COc1ccc(C2Sc3ccccc3N(CCN(C)C)C(=O)C2OC(C)=O)cc1</smiles>

e<smiles>COC(=O)C1=C(C)NC(C)=C(C(=O)OC)C1c1ccccc1</smiles>

f<smiles>CCOC(=O)C1=C(COCCN)NC(C)=C(C(=O)OC)C1c1ccccc1</smiles>

g
CALCIUM CHANNEL BLOCKERS<smiles>CN(C)CCCN1c2ccccc2CCc2ccccc21</smiles>

i<smiles>CN(C)CCC=C1c2ccccc2CCc2ccccc21</smiles>

k<smiles>CN1CCC(=C2c3ccccc3C=Cc3ccccc32)CC1</smiles>

I<smiles>CN1CCC(=C2c3ccccc3CCc3cccnc32)CC1</smiles>

m<smiles>COC(=O)C1=C(C)NC(C)=C(C(=O)OCCN(C)Cc2ccccc2)C1c1cccc([N+](=O)[O-])c1</smiles>
h

antidepressants

antihistamines

DIBENZAZEPINES AND ANALOGUES<smiles>CN(C)CCCN1c2ccccc2Sc2ccc(Cl)cc21</smiles><smiles>CN1CCN(CCCN2c3ccccc3Sc3ccc(C(F)(F)F)cc32)CC1</smiles>

q

$$
\text { antipsychotics }
$$

PHENOTHIAZINES
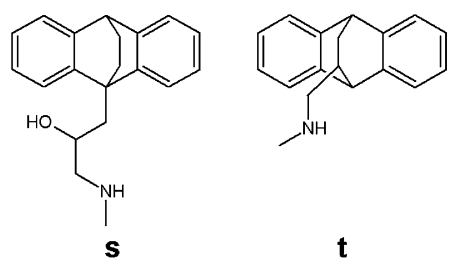

$\mathbf{t}$<smiles>CN(C)CC1c2ccccc2C2c3ccccc3C1c1ccccc12</smiles>

$\mathbf{u}$<smiles>CN(C)CC1c2ccccc2C2c3ccccc3C1c1ccccc12</smiles>

v<smiles>CN1CCC(=C2c3ccccc3CCc3sccc32)CC1</smiles>

n<smiles>CN1CCC(=C2c3ccccc3CC(=O)c3sccc32)CC1</smiles>

o 
<smiles>CN1Cc2c(N)cccc2C(c2ccccc2)C1</smiles>

a<smiles>CN(C)CCCC1(c2ccc(F)cc2)OCc2cc(C#N)ccc21</smiles>

b

antidepressants<smiles>CN(C)CCC(c1ccc(Cl)cc1)c1ccccn1</smiles>

d

antihistamine<smiles>COc1cc(NC(C)CCCN)c2ncccc2c1</smiles>

e

\section{MISCELLANEOUS DRUGS}

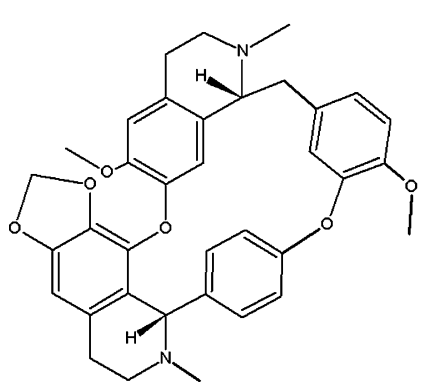

$\mathbf{f}$

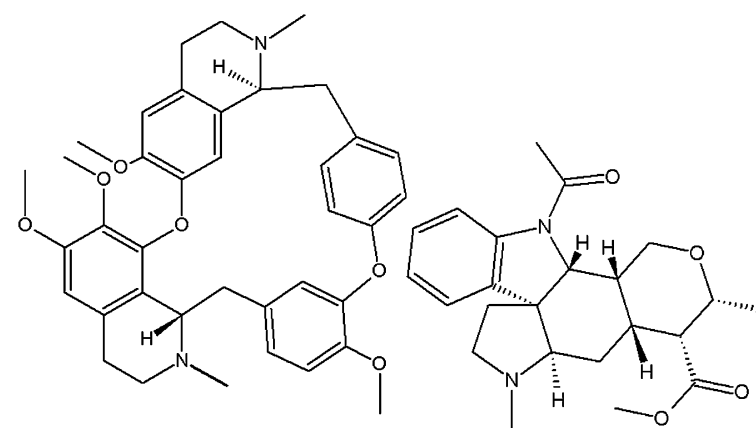

h

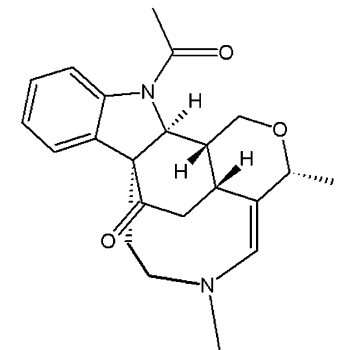

i

\section{PLANT-DERIVED ALKALOIDS}<smiles>CCCN(CCC)S(=O)(=O)c1ccc(C(=O)O)cc1</smiles>

j

uricosuric<smiles>CCCCCCCCCCCC(C)OC(CO)c1ccccc1</smiles>

k

surfactant

\section{NON-TYPICAL CQR REVERSERS}

Fig. 3. Additional synthetic and plant-derived compounds with reported CQR reversing activity. Where the compounds are drugs with other pharmacological applications, these are indicated. As stated, NP-30 is a detergent. The compounds are (a) nomifensine (Taylor et al., 2000), (b) citalopram (Taylor et al., 2000), (c) fluoxetine (Gerena et al., 1992), (d) chlorpheniramine (Basco and Le Bras, 1994), (e) primaquine (Bray et al., 2005), (f) cepharanthin (Haruki et al., 2000), (g) tetrandrine (Ye et al., 1989), (h) malagashine (Rasonaivo et al., 1994), (i) strychnobasiline (Rasonaivo et al., 1994), (j) probenecid (Nzila et al., 2003) and (k) NP-30 (Ciach et al., 2003). NP-30 is also reported to reverse quinine resistance. Tetrandrine sensitises both CQR and CQS parasites to CQ activity and thus differs significantly from the other compounds in its activity.

resistance reverser presented in Figs. 2 and 3 appear to exhibit this pharmacophore as indicated in Fig. 4.

A study by Alibert et al. in 2002 using a series of 28 novel rigid dihydroanthracene derivatives (Fig. 5) has aided in further elucidating the pharmacophore and in establishing some possible characteristics of the binding site for resistance reversers. In this study the aromatic nucleus was left unchanged, while the position and nature of the $\mathrm{N}$ group attached to the ethano or etheno bridge was altered. The key SARs are illustrated in Fig. 5. Using a molecular modelling approach, the authors defined a putative interaction site for the $\mathrm{N}$ atom in which there is hydrogen bonding to a hydroxyl group of a serine residue and a salt bridge formed between the same protonated, positively charged $\mathrm{N}$ and an aspartate residue (Fig. 5). Interestingly, this site can accommodate a number of other resistance reversers, including VPL and promethazine. On the other hand, related dihydroanthracenes that cannot form these interactions with the putative 


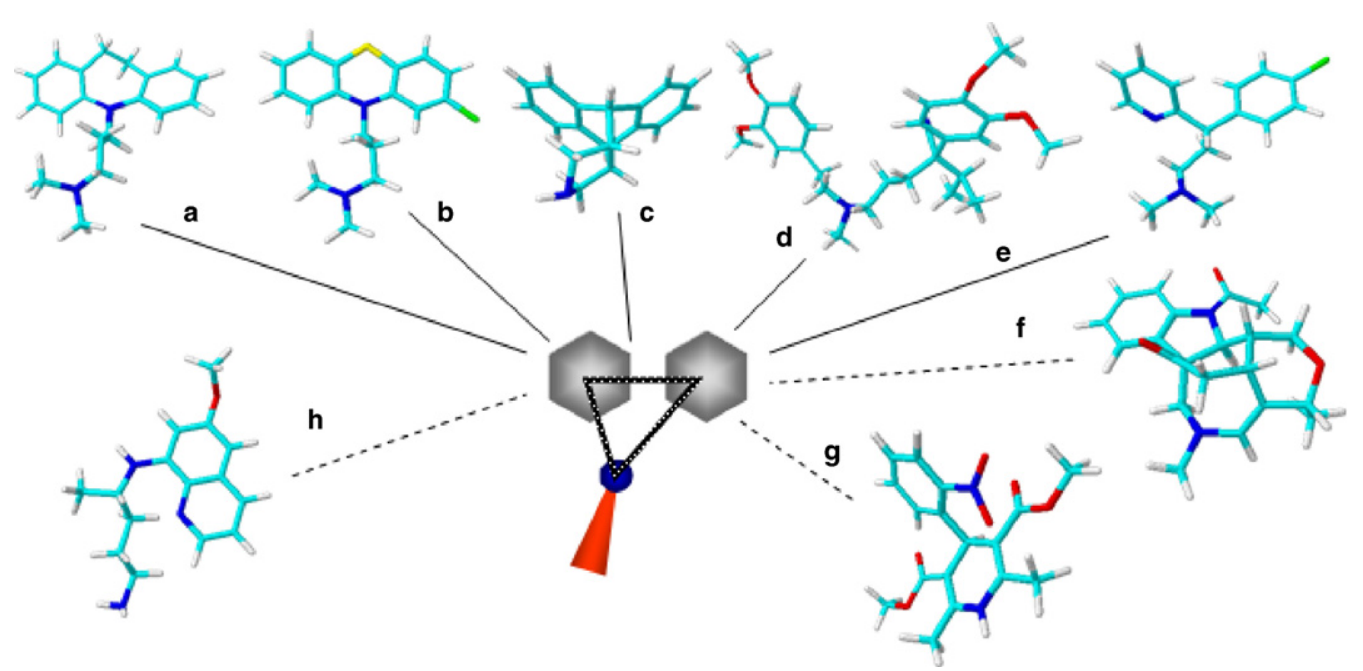

Fig. 4. A schematic representation of the pharmacophore for CQR reversal proposed by Bhattacharjee et al. (2002), consisting of two aromatic hydrophobic groups (represented by the grey hexagons) and a nitrogen $\mathrm{H}$-bond acceptor (represented by a blue sphere and red cone). Presumably the $\mathrm{N}$ atom would act as a H-bond donor if protonated. A series of representative compounds of various classes are shown to illustrate the proposed pharmacophore. These include (a) imipramine, (b) chlorpromazine, (c) a dihydroanthracene derivative, (d) VPL and (e) fluoxetine. Strychnobasiline (f), nifedipine (g) and primaquine (h) appear to partially fulfil the requirements in that they have one aromatic ring and the required $\mathrm{N}$ atom.

site show no resistance reversing activity. The mandatory requirement for the aromatic rings was illustrated by the inactivity of mecamylamine, which contains the bicyclic saturated ring system with a secondary $\mathrm{N}$ function, but lacks any aromatic rings. The authors suggested that the proposed binding site is consistent with mutant PfCRT in CQR par- asites which have alleles encoding a CVIET haplotype at residues 72-76. The functional groups on the glutamate and threonine residue side-chains would presumably form a site resembling that produced by the putative aspartate and serine residues in the hypothetical binding site generated by the SAR study.

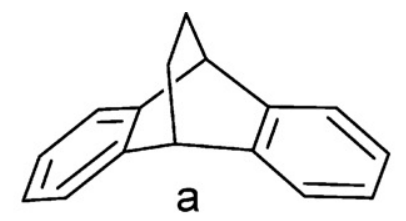

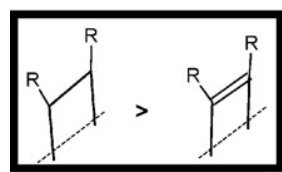

b

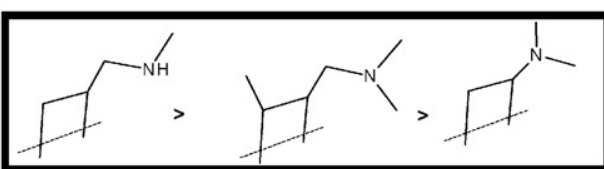

C

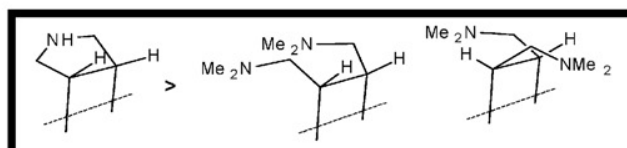

d

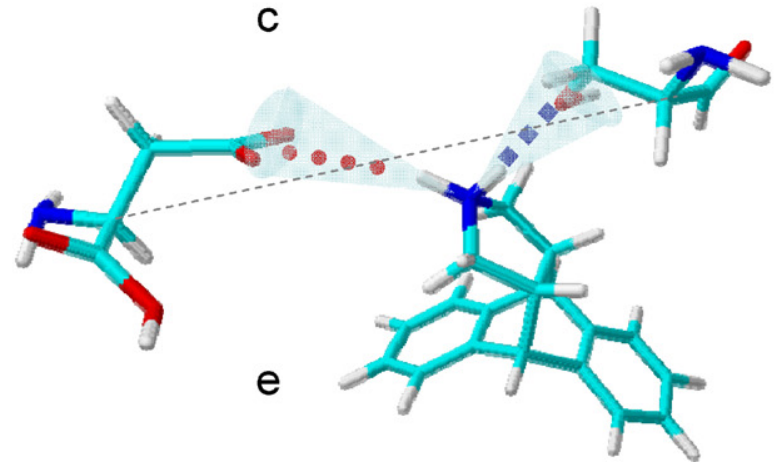

Fig. 5. SARs in dihydroanthracene derivatives and the CQR reverser-binding site proposed by Alibert et al. (2002). The use of rigid 9,10-dihydro-9,10ethanoanthracene (a) and 9,10-dihydro-9,10-ethenoanthracene nuclei allowed the relationship between activity and structure of the ethano and etheno groups to be probed in detail. Results showed the ethano compounds to be better resistance reversers than etheno compounds (b). Secondary amines are more active than tertiary amines, while the molecule is more active if the $\mathrm{N}$ atom is at the $\beta$ position, rather than the $\alpha$ position in the chain (c). Finally, a cyclic amine is more active than acyclic structures (d). The authors proposed a model of the binding site which is depicted schematically in (e). The amino group is proposed to hydrogen bond (blue dashes) to the hydroxyl group of a serine (or threonine) residue and to interact electrostatically with the carboxylate group of an aspartate (glutamate) residue (red dashes). The separation between the two residues (dotted line) is predicted to be $9.2 \AA$. 
Recent work has indicated that $\mathrm{CQR}$ reversal may involve direct competition of the resistance reverser for the CQbinding site in PfCRT. The binding site proposed by Alibert et al. readily accommodates $\mathrm{CQ}$, but not analogues with shortened side chains that are active against $\mathrm{CQR}$ parasites (Alibert et al., 2002). This is consistent with the observation that side chain length of CQ analogues is important in determining the resistance profile to these drugs (De et al., 1996). More specifically, the separation of the tertiary amine from the quinoline ring appears to be the important determinant in CQR. Compounds with a separation between 4 and 8 carbons from the quinoline ring exhibit varying degrees of crossresistance with CQ in CQR strains. Separations greater than 8 or smaller than 4 carbons from the ring and the compounds are equally effective against the CQS and CQR strains (De et al., 1996). The close structural relationship between chemosensitizers and the antimalarial CQ has been further highlighted by Kalkinidis et al. who have been able to modify a chemosensitizer to convert it into an antimalarial (Kalkanidis et al., 2002). However, the most effective antimalarial analogue synthesized from the chemosensitizer scaffold was found to have lost most of its modulating action on CQ activity in the CQR strain. Further support for a direct competition is the fact that the aromatic nucleus of CQ, 4-amino-7-chloroquinoline, is itself a resistance reverser (Kalkanidis et al., 2004).

A puzzling aspect of the study by Alibert et al. is that CQR reversal activity and increased CQ accumulation in the parasite do not appear to be directly correlated (Alibert et al., 2002). The authors suggested that some compounds may increase CQ accumulation without increasing its accessibility to haem and vice versa. This is somewhat difficult to envisage. An intriguing possibility is that some dihydroanthracenes may interact with haem without inhibiting haemozoin formation, but competing with CQ and hence reducing its overall accumulation and thus appearing to decouple accumulation from resistance-reversing activity. In this regard, it is known that some quinolines can bind haem without inhibiting haemozoin formation (Egan et al., 2000).

A recent report on the effects of pfcrt mutations on CQR, VPL reversibility and activities of CQ analogues with shortened and lengthened side chains has further elucidated these issues (Lakshmanan et al., 2005). Recombinant lines in which the wild type $\mathrm{K} 76$ residue has been restored in haplotypes which are otherwise identical to $\mathrm{CQR}$ lines fully restores $\mathrm{CQ}$ sensitivity. In Dd2 derived lines, the parasites have similar QN sensitivity in recombinant lines containing either $\mathrm{K} 76$ or the K76T mutation, but only the lines in which the K76T mutation is present show increased QN sensitivity in the presence of VPL. This demonstrates that the threonine residue at position 76 is critical to the reversal activity of VPL. The 7G8 line shows a similar effect, but interestingly this parent line itself shows much weaker VPL reversibility. Intriguingly, it contains an uncharged asparagine residue at position 75, rather than a charged glutamate residue. Recombinant lines containing E75 and T76 appear to have enhanced VPL reversibility of CQR, but also show little increase in QN activity. Overall, these data seem to support the proposal of Alibert et al. that E75 and T76 form an important part of the VPL binding site (Alibert et al., 2002). The K76T mutation is also shown to be the decisive factor in determining susceptibility to CQ analogues with different chain lengths. Overall accumulation of CQ and haem binding to CQ could also be directly correlated with this key mutation.

It would therefore appear that most $\mathrm{CQR}$ reversers probably bind to the same site on PfCRT as CQ, effectively blocking CQ binding by competition. The key mutations in $p f c r t$ appear to result in the formation of this binding site and of these mutations, K76T is the most important. It should be noted that most reversers work at micromolar concentrations which are much higher than the expected amount of free, non-haem bound CQ. A reason for this disparity is not clear but could be related to the reverser affinity for the CQ binding site. Clearly there are very strict structural requirements for interaction at this site or else we would have observed greater cross-resistance to similar aminoquinolines or chloroquine analogues.

Interestingly, there are also some compounds known to reverse CQR (e.g. NP30, probenecid and cimetidine) that do not have the structural characteristics mentioned above (Ndifor et al., 1993; Crandall et al., 2000; Nzila et al., 2003). Moreover some of these compounds are able to reverse the resistance to both CQ and mefloquine which is not typical of the "conventional" chemosensitizers mentioned above (Ciach et al., 2003). Some compounds that reduce intracellular glutathione levels are also able to sensitize the parasites to CQ (Ginsburg et al., 1998; Deharo et al., 2003). It remains to be established how these agents can reverse resistance and whether it is specific for CQ alone.

\section{Reversal of mefloquine and quinine resistance}

The phenomenon of resistance reversal is not specific to CQR parasites. Resistance reversal in P. falciparum has also been observed for several of the other quinoline-based antimalarials. Reversal of MQR had for many years been observed with only one chemosensitizer, namely penfluridol (Peters and Robinson, 1991; Oduola et al., 1993). As with $\mathrm{CQR}$ strains, the shift in sensitivity with penfluridol is only observed in the MQR strain. No effect is seen in MQ sensitive strains. VPL has no effect on modulating MQR either in vivo (Peters and Robinson, 1991) or in vitro (Oduola et al., 1993), nor does penfluridol modulate CQ resistance. It is not known whether the effect of penfluridol in enhancing MQ action is linked with an increase in MQ accumulation as is the case with CQ in CQR reversal (Oduola et al., 1993).

Recently there have been reports of reversal of MQR by several other agents (Fig. 6), including the detergent NP30, a nonylphenolethoxylate (Ciach et al., 2003). Since these agents are also able to reverse CQR (Crandall et al., 2000) it is unlikely that the method of resistance reversal is similar to that of either penfluridol or VPL since these effects are 


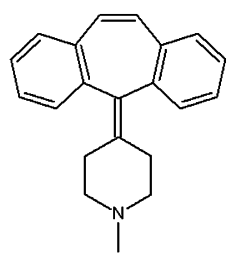

a

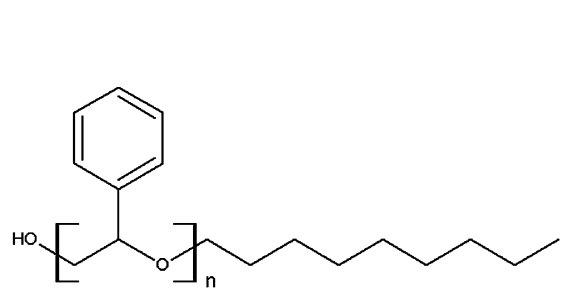

b

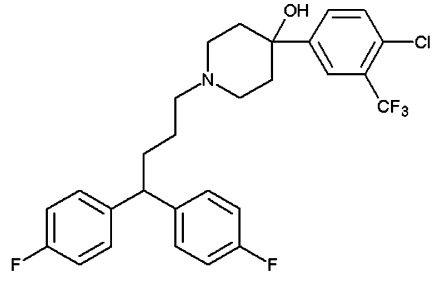

C antipsychotic

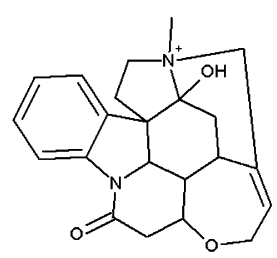

e

\section{antihistamine}

\section{surfactant}

\section{MQR REVERSERS}

Fig. 6. Compounds with reported MQR reversing activity (a) cyproheptidine (Baldwin et al., 1991), (b) NP-30 (Ciach et al., 2003), (c) penfluridol (Peters and Robinson, 1991; Oduola et al., 1993) and (d) icajine (Frederich et al., 2001).

specific to MQ- or CQ-resistant strains respectively. NP-30 has not been demonstrated to increase CQ uptake into CQR strains (Crandall et al., 2000).

QN resistance appears to share characteristics with both $\mathrm{CQR}$ and MQR. Resistance to quinine is determined by mutations in both Pgh-1 (Reed et al., 2000) and PfCRT (Cooper et al., 2002). Mutations in PfCRT are central in determining the resistance reversal phenotype with the stereoisomers $\mathrm{QN}$ and quinidine (QD). Both QN and QD resistance can be modulated by VPL (Cooper et al., 2002). Plasmodial strains expressing the K76T mutation are both CQR and less sensitive to quinine and quinidine. VPL is able to sensitize the parasites to all three of these quinolines. In strains carrying the K76N mutation, the parasites are resistant to CQ and QN but show no change in QD IC $_{50}$ compared with a sensitive strain. Yet VPL is still able to increase the susceptibility of the parasite to all three compounds. Lastly, the mutation K76I causes resistance to CQ and QD, but drastically reduces the parasite's resistance to QN. VPL can sensitize these parasites to both CQ and QD but increases the parasite's resistance to QN (Cooper et al., 2002).

Other compounds that reverse CQR also reverse resistance to QN and QD (Fig. 2). Various calcium channel antagonists can reverse resistance in vitro (Kyle et al., 1990). It would thus appear that CQ resistance reversal is very closely linked to the reversal of QN and QD resistance.

Aside from the surfactant NP-30 which appears to act via a completely distinct mechanism (Ciach et al., 2003), there have not been any MQR reversers that have been demonstrated to reverse QN resistance.

\section{Clinical applications}

Ever since verapamil was first discovered to reverse CQR (Martin et al., 1987), there has been a question about the therapeutic viability of resistance reversal. Studies in Aotus monkeys with CQR P. falciparum could not demonstrate a cure with a VPL analogue but this could be due to unfavourable pharmacokinetics or bioavailability (Williams et al., 1992).

Ye and Van Dyke suggested that VPL toxicity to human host calcium channels might be avoided by using the (R)-(+) isomer since calcium channels are specifically blocked by the (S)-(-) isomer (Ye and Van Dyke, 1988). However, since many of these chemosensitizers block P-glycoprotein from secreting or excreting toxins from certain tissue types, they have the potential to lead to a toxic accumulation of both CQ and the reversing agent in these cell types (Watt et al., 1990). Thus, for example, although CQ and verapamil are non-toxic to HEP-G2 liver cells individually, they became toxic when combined (Watt et al., 1990).

Another important factor is the binding of the chemosensitizers to plasma proteins. Many of the in vitro studies in $P$. falciparum do not accurately mimic the conditions in human blood. While desipramine is able to reverse CQR in vitro and in Aotus monkeys (Bitonti et al., 1988), no such effect was seen in a trial in humans (Warsame et al., 1992). Boulter et al. demonstrated that the effect of desipramine on enhancing CQ action was reduced in the presence of plasma proteins (Boulter et al., 1993). VPL is 90\% protein bound in plasma (Keefe et al., 1981). It binds to both albumin and $\alpha_{1}$-acid glycoprotein (Gross et al., 1988). A study in MDR cancer cells has shown that serum protein binding can severely deplete the medium of the chemosensitizer and thus undermine the effect on resistance reversal (Lehnert et al., 1996). In this regard, it has been suggested that the reason for the more successful trial of CQ combined with chlorpheniramine in humans was the reduced capacity of the chlorpheniramine to bind to plasma proteins (Sowunmi and Oduola, 1997). However, recent evidence has demonstrated that the in vitro intrinsic antimalarial activity of chlorpheniramine as well as its CQresistance reversing potential was significantly reduced in the presence of increasing concentrations of $\alpha_{1}$-acid glycoprotein (Gbotosho et al., 2006). Similar results were shown for the resistance reversers VPL, desipramine and promethazine. This further reinforces the importance of plasma protein binding in the activity of CQ-resistance reversers. 
Two separate African studies have reported promising results when chlorpheniramine was combined with CQ to reverse CQR in humans (Abok, 1997; Sowunmi and Oduola, 1997). In the one case, CQ therapy in patients was supplemented with a treatment of chlorpheniramine. The parasite clearance improved from $30 \%$ in the CQ only group to $70 \%$ in the chemosensitizer-supplemented therapy after 4 days (Abok, 1997). Sowunmi and Oduola performed a clinical trial in children with acute uncomplicated falciparum malaria (Sowunmi and Oduola, 1997). They found that $85.4 \%$ of the children treated with the CQ-chlorpheniramine combination were cured at day 14 compared to $75.5 \%$ in the group treated with CQ alone. The combination was also well-tolerated, suggesting promise as a new treatment regimen. However, it should be noted that the concentrations of chlorpheniramine used in vitro to effectively reverse CQ resistance are unlikely to be achieved with the dosage regimens used in the abovementioned human trials. Therefore, there is possibly another mechanism governing the enhanced efficacy of CQ in combination with chlorpheniramine in these studies.

Lastly, promethazine $(1 \mu \mathrm{M})$ was shown to enhance CQ action in vitro against several CQR Nigerian strains and in Aotus monkeys infected with CQR falciparum malaria (Oduola et al., 1998). It was also shown that plasma taken at various time points after the administration of promethazine to human volunteers, could reverse $\mathrm{CQR}$ in vitro. The largest reduction in $\mathrm{IC}_{50}$ was found with plasma samples taken $3-4 \mathrm{~h}$ after promethazine administration. This suggests that promethazine can reach levels high enough in the bloodstream to enhance CQ activity.

The use of "cocktails" of chemosensitizers in combination with CQ has been proposed (Adovelande et al., 1998; Van Schalkwyk et al., 2001). While most of the individual chemosensitizers are toxic to humans at concentrations that optimally reverse CQR, various authors have suggested combining the chemosensitizers at concentrations which are suboptimal in reversing resistance (Adovelande et al., 1998; Van Schalkwyk et al., 2001). The chemosensitizers act additively in enhancing CQ action. In this manner the toxicity of any single agent can be avoided. The "cocktail" would have to contain agents that are functionally different since using two or more calcium channel blockers, for instance, would have the same toxic effect as using one at a high dose.

For any CQ-resistance reversal therapy to be therapeutically viable as an antimalarial treatment, some important pharmacokinetic factors will need to be considered. Since CQ activity against CQR strains is closely linked with the presence of the reversing agent, both drugs should ideally be matched for their absorption rates and have similar half lives. This should ensure that CQ activity is maximal as it is absorbed. One way of overcoming this problem could be to chemically couple the reversing agent with CQ. In this way the two drugs would be absorbed simultaneously. A recent paper has demonstrated the potential of this strategy as a new treatment for CQR strains (Burgess et al., 2006).
To date, using the reported CQ-resistance reversing agents at their optimal in vitro concentrations in humans would lead to significant toxicity. Therefore, new reversing agents would need to be optimally designed to exert their effect at lower concentrations or be less toxic to humans. Also given that the resistance reversing agents are designed to be absorbed along with CQ, and that they possess similar structural characteristics to CQ as described previously, the potential for cumulative toxicity is enhanced.

The addition of a resistance reverser to CQ therapy would undoubtedly add to the cost of the treatment. Given that most of the victims of malaria are from Third World countries and would not be able to afford expensive therapies, this would negate one of the obvious advantages of CQ itself.

While the safety, efficacy and cost-effectiveness of CQ was undisputed in the past, maintaining these advantageous characteristics while reviving this antimalarial in combination with resistance reversers could prove to be a great challenge.

\section{Conclusions}

The last 5 years have seen major advances in our understanding of CQR and of the SARs in resistance reversing agents. While the mechanisms involved have not been definitively determined, the evidence is beginning to suggest that the following hypothesis may hold some validity: CQR almost certainly seems to arise from the K76T mutation (and potentially other mutations of K76 to neutral residues) in PfCRT. It would appear that PfCRT may very well be a transporter through which, in the mutated forms, cationic protonated CQ can diffuse down its concentration gradient. CQ appears able to bind to these mutant forms of PfCRT, very likely to a site involving position 76 . CQR reversers appear to compete with CQ for this binding site, probably through interactions via their hydrophobic aromatic groups as well as hydrogen bonding and probably electrostatic interactions. This defines a pharmacophore that involves at least one, but usually two aromatic rings as well as a protonatable $\mathrm{N}$ atom, normally a secondary or tertiary $\mathrm{N}$. When present with the correct spatial orientation, these features confer chemosensitizing properties. Requirements for reversal of QN resistance appear to be similar, but MQR and its reversal are still poorly understood. To date, routine clinical application of chemosensitizers has been prevented by toxicity problems and it remains to be seen whether these advances in our understanding can eventually lead to advances in the clinic.

\section{Acknowledgement}

We thank Dr. Kevin Saliba, School of Biochemistry and Molecular Biology, Faculty of Science, The Australian National University, Canberra, ACT, 0200 Australia for critically reading the manuscript and making valuable comments. 


\section{References}

Abok, K., 1997. Re: Malaria treatment in peri-urban area of Kisumu town. East Afr. Med. J. 74, 757.

Adovelande, J., Bastide, B., Deleze, J., Schrevel, J., 1993. Cytosolic free calcium in Plasmodium falciparum-infected erythrocytes and the effect of verapamil: a cytofluorimetric study. Exp. Parasitol. 76, 247-258.

Adovelande, J., Deleze, J., Schrevel, J., 1998. Synergy between two calcium channel blockers, verapamil and fantofarone (SR33557), in reversing chloroquine resistance in Plasmodium falciparum. Biochem. Pharmacol. $55,433-440$.

Alibert, S., Santelli-Rouvier, C., Pradines, B., Houdoin, C., Parzy, D., Karolak-Wojciechowska, J., Barbe, J., 2002. Synthesis and effects on chloroquine susceptibility in Plasmodium falciparum of a series of new dihydroanthracene derivatives. J. Med. Chem. 45, 3195-3209.

Baldwin, J.J., Eilon, G.F., Friedman, P.A., Remy, D.C., 1991. Method of treating malaria with cyproheptadine derivatives. US Patent 5021426, Merck.

Barnes, D.A., Foote, S.J., Galatis, D., Kemp, D.J., Cowman, A.F., 1992. Selection for high-level chloroquine resistance results in deamplification of the $p f m d r l$ gene and increased sensitivity to mefloquine in Plasmodium falciparum. EMBO J. 11, 3067-3075.

Basco, L.K., Le Bras, J., 1991. Plasmodium falciparum: in vitro drug interaction between chloroquine and enantiomers of amlodipine. Exp. Parasitol. $72,262-270$.

Basco, L.K., Le Bras, J., 1994. In vitro reversal of chloroquine resistance with chlorpheniramine against African isolates of Plasmodium falciparum. Jpn. J. Med. Sci. Biol. 47, 59-63.

Bayoumi, R.A.L., Babiker, H.A., Arnot, D.E., 1994. Uptake and efflux of chloroquine by chloroquine-resistant Plasmodium falciparum clones recently isolated in Africa. Acta Trop. 58, 141-149.

Bennett, T.N., Kosar, A.D., Ursos, L.M.B., Dzekunov, S.M., Singh Sidhu, A.B., Fidock, D.A., Roepe, P.D., 2004. Drug resistance-associated pfCRT mutations confer decreased Plasmodium falciparum digestive vacuolar pH. Mol. Biochem. Parasitol. 133, 99-114.

Bhattacharjee, A.K., Kyle, D.E., Vennerstrom, J.L., 2001. Structural analysis of chloroquine resistance reversal by imipramine analogs. Antimicr. Agents Chemother. 45, 2655-2657.

Bhattacharjee, A.K., Kyle, D.E., Vennerstrom, J.L., Milhous, W.K., 2002. A 3D QSAR pharmacophore model and quantum chemical structureactivity analysis of chloroquine(CQ)-resistance reversal. J. Chem. Inf. Comput. Sci. 42, 1212-1220.

Biot, C., Bauer, H., Schirmer, R.H., Davioud-Charvet, E., 2004. 5Substituted tetrazoles as bioisosteres of carboxylic acids. Bioisosterism and mechanistic studies on glutathione reductase inhibitors as antimalarials. J. Med. Chem. 47, 5972-5983.

Biot, C., Glorian, G., Maciejewski, L.A., Brocard, J.S., 1997. Synthesis and antimalarial activity in vitro and in vivo of a new ferrocene-chloroquine analogue. J. Med. Chem. 40, 3715-3718.

Bitonti, A.J., Sjoerdsma, A., McCann, P.P., Kyle, D.E., Oduola, A.M.J., Rossan, R.N., Milhous, W.K., Davidson, D.E., 1988. Reversal of chloroquine resistance in malaria parasite Plasmodium falciparum by desipramine. Science 242, 1301-1303.

Boulter, M.K., Bray, P.G., Howells, R.E., Ward, S.A., 1993. The potential of desipramine to reverse chloroquine resistance of Plasmodium falciparum is reduced by its binding to plasma protein. Trans R. Soc. Trop. Med. Hyg. 87, 303.

Bray, P.G., Deed, S., Fox, E., Kalkanidis, M., Mungthin, M., Deady, L.W., Tilley, L., 2005. Primaquine synergises the activity of chloroquine against chloroquine-resistant $P$. falciparum. Biochem. Pharmacol. 70, $1158-1166$.

Bray, P.G., Hawley, S.R., Ward, S.A., 1996. 4-Aminoquinoline resistance of Plasmodium falciparum: insights from the study of amodiaquine uptake. Mol. Pharmacol. 50, 1551-1558.

Bray, P.G., Howells, R.E., Ritchie, G.Y., Ward, S.A., 1992a. Rapid chloroquine-efflux phenotype in both chloroquine-sensitive and chloroquine-resistant Plasmodium falciparum. A correlation of chloroquine-sensitivity with energy-dependent drug accumulation. Biochem. Pharmacol. 44, 1317-1324.

Bray, P.G., Howells, R.E., Ward, S.A., 1992b. Vacuolar acidification and chloroquine sensitivity in Plasmodium falciparum. Biochem. Pharmacol. 43, 1219-1227.

Bray, P.G., Mungthin, M., Ridley, R.G., Ward, S.A., 1998. Access to hematin: the basis of chloroquine resistance. Mol. Pharmacol. 54, 170-179.

Bray, P.G., Saliba, K.J., Davies, J.D., Spiller, D.G., White, M.R., Kirk, K., Ward, S.A., 2002. Distribution of acridine orange fluorescence in Plasmodium falciparum-infected erythrocytes and its implications for the evaluation of digestive vacuole pH. Mol. Biochem. Parasitol. 119, 301-304.

Burgess, S.J., Selzer, A., Kelly, J.X., Smilkstein, M.J., Riscoe, M.K., Peyton, D.H., 2006. A chloroquine-like molecule designed to reverse resistance in Plasmodium falciparum. J. Med. Chem. 49, 5623-5625.

Cano-Gauci, D.F., Riordan, J.R., 1987. Action of calcium antagonists on multidrug resistant cells. Specific cytotoxicity independent of increased cancer drug accumulation. Biochem. Pharmacol. 36, 2115-2123.

Carlton, J., Mackinnon, M., Walliker, D., 1998. A chloroquine resistance locus in the rodent malaria parasite Plasmodium chabaudi. Mol. Biochem. Parasitol. 93, 57-72.

Chen, N., Kyle, D.E., Pasay, C., Fowler, E.V., Baker, J., Peters, J.M., Cheng, Q., 2003. pfcrt allelic types with two novel amino acid mutations in chloroquine-resistant Plasmodium falciparum isolates from the Philippines. Antimicr. Agents Chemother. 47, 3500-3505.

Chen, N., Russell, B., Fowler, E., Peters, J., Cheng, Q., 2002. Levels of chloroquine resistance in Plasmodium falciparum are determined by loci other than $p f c r t$ and $p f m d r 1$. J. Infect. Dis. 185, 405-406.

Ciach, M., Zong, K., Kain, K.C., Crandall, I., 2003. Reversal of mefloquine and quinine resistance in Plasmodium falciparum with NP30. Antimicr. Agents Chemother. 47, 2393-2396.

Cooper, R.A., Ferdig, M.T., Su, X.Z., Ursos, L.M.B., Mu, J., Nomura, T., Fujioka, H., Fidock, D.A., Roepe, P.D., Wellems, T.E., 2002. Alternative mutations at position 76 of the vacuolar transmembrane protein PfCRT are associated with chloroquine resistance and unique stereospecific quinine and quinidine responses in Plasmodium falciparum. Mol. Pharmacol. 61, 35-42.

Cooper, R.A., Hartwig, C.L., Ferdig, M.T., 2005. pfcrt is more than the Plasmodium falciparum chloroquine resistance gene: a functional and evolutionary perspective. Acta Trop. 94, 170-180.

Cowman, A.F., Karcz, S., Galatis, D., Culvenor, J.G., 1991. A P-glycoprotein homologue of Plasmodium falciparum is localized on the digestive vacuole. J. Cell Biol. 113, 1033-1042.

Crandall, I., Charuk, J., Kain, K.C., 2000. Nonylphenolethoxylates as malarial chloroquine resistance reversal agents. Antimicr. Agents Chemother. 44, 2431-2434.

De, D., Krogstad, F.M., Cogswell, F.B., Krogstad, D.J., 1996. Aminoquinolines that circumvent resistance in Plasmodium falciparum in vitro. Am. J. Trop. Med. Hyg. 55, 579-583.

Deharo, E., Barkan, D., Krugliak, M., Golenser, J., Ginsburg, H., 2003. Potentiation of the antimalarial action of chloroquine in rodent malaria by drugs known to reduce cellular glutathione levels. Biochem. Pharmacol. $66,809-817$.

Durrand, V., Berry, A., Sem, R., Galziou, P., Beaudou, J., Fandeur, T., 2004. Variations in the sequence and expression of the Plasmodium falciparum resistance transporter (Pfcrt) and the relationship to chloroquine resistance in vitro. Mol. Biochem. Parasitol. 136, 273-285.

Dzekunov, S.M., Ursos, L.M.B., Roepe, P.D., 2000. Digestive vacuolar pH of intact intraerythrocytic $P$. falciparum either sensitive or resistant to chloroquine. Mol. Biochem. Parasitol. 110, 107-124.

Egan, T.J., 2003. Haemozoin (malaria pigment): a unique crystalline drug target. Drug Disc. Today Targets 2, 115-124.

Egan, T.J., 2004. Haemozoin formation as a target for the rational design of new antimalarials. Drug Design Revs Online 1, 93-110.

Egan, T.J., Hunter, R., Kaschula, C.H., Marques, H.M., Misplon, A., Walden, J.C., 2000. Structure-function relationships in aminoquinolines: effect of amino and chloro groups on quinoline-hematin complex formation, 
inhibition of $\beta$-hematin formation, and antiplasmodial activity. J. Med. Chem. 43, 283-291.

Fidock, D.A., Nomura, T., Cooper, R.A., Su, X.-Z., Talley, A.K., Wellems, T.E., 2000a. Allelic modifications of the $c g 2$ and $c g 1$ genes do not alter the chloroquine response of drug-resistant Plasmodium falciparum. Mol. Biochem. Parasitol. 110, 1-10.

Fidock, D.A., Nomura, T., Talley, A.K., Cooper, R.A., Dzekunov, S.M., Ferdig, M.T., Ursos, L.M.B., Sidhu, A.B.S., Naudé, B., Deitsch, K.W., Su, X.-Z., Wootton, J.C., Roepe, P.D., Wellems, T.E., 2000b. Mutations in the P. falciparum digestive vacuole transmembrane protein PfCRT and evidence for their role in chloroquine resistance. Mol. Cell 6, 861-871.

Fitch, C.D., 1969. Chloroquine resistance in malaria: a deficiency of chloroquine binding. Proc. Natl. Acad. Sci. U.S.A. 64, 1181-1187.

Fleckenstein, A., Kammermeier, H., Doring, H.J., Freund, H.J., 1967. On the method of action of new types of coronary dilatators with simultaneous oxygen-saving myocardial effects, prenylamine and iproveratril. 2. Z. Kreislauf. 56, 839-858.

Foote, S.J., Thompson, J.K., Cowman, A.F., Kemp, D.J., 1989. Amplification of the multidrug resistance gene in some chloroquine-resistant isolates of P. falciparum. Cell 57, 921-930.

Frederich, M., Hayette, M.-P., Tits, M., De Mol, P., Angenot, L., 2001. Reversal of chloroquine and mefloquine resistance in Plasmodium falciparum by the two monoindole alkaloids, icajine and isoretuline. Planta Med. $67,523-527$.

Gbotosho, G.O., Ogundahunsi, O.A., Happi, C.T., Kyle, D.E., Gerena, L., Milhous, W.K., Sowunmi, A., Oduola, A.M., Salako, L.A., 2006. The effects of alpha(1)-acid glycoprotein on the reversal of chloroquine resistance in Plasmodium falciparum. Ann. Trop. Med. Parasitol. 100, 571-578.

Gerena, L., Bass, G.T., Kyle, D.E., Oduola, A.M.J., Milhous, W.K., Martin, R.K., 1992. Fluoxetine hydrochloride enhances in vitro susceptibility to chloroquine in resistant Plasmodium falciparum. Antimicr. Agents Chemother. 36, 2651-2655.

Ginsburg, H., Famin, O., Zhang, F., Krugliak, M., 1998. Inhibition of glutathione-dependent degradation of heme by chloroquine and amodiaquine as a possible basis for their antimalarial mode of action. Biochem. Pharmacol. 56, 1305-1313.

Ginsburg, H., Stein, W.D., 1991. Kinetic modelling of chloroquine uptake by malaria-infected erythrocytes. Assessment of the factors that may determine drug resistance. Biochem. Pharmacol. 41, 1463-1470.

Gross, A.S., Heuer, B., Eichelbaum, M., 1988. Stereoselective protein binding of verapamil enantiomers. Biochem. Pharmacol. 37, 4623-4627.

Guan, J., Kyle, D.E., Gerena, L., Zhang, Q., Milhous, W.K., Lin, A.J., 2002. Design, synthesis, and evaluation of new chemosensitizers in multi-drugresistant Plasmodium falciparum. J. Med. Chem. 45, 2741-2748.

Happi, T.C., Thomas, S.M., Gbotosho, G.O., Falade, C.O., Akinboye, D.O., Gerena, L., Hudson, T., Sowunmi, A., Kyle, D.E., Milhous, W., Wirth, D.F., Oduola, A.M.J., 2003. Point mutations in the pfcrt and pfmdr-1 genes of Plasmodium falciparum and clinical response to chloroquine, among malaria patients from Nigeria. Ann. Trop. Med. Parasitol. 97, 439-451.

Haruki, K., Bray, P.G., Ono, M., Ward, S.A., 2000. Potent enhancement of the sensitivity of Plasmodium falciparum to chloroquine by the bisbenzylisoquinoline alkaloid cepharanthin. Antimicr. Agents Chemother. 44, 2706-2708

Hayward, R., Saliba, K.J., Kirk, K., 2005. Mutations in pfmdr1 modulate the sensitivity of Plasmodium falciparum to the intrinsic antiplasmodial activity of verapamil. Antimicr. Agents Chemother. 49, 840-842.

Hayward, R., Saliba, K.J., Kirk, K., 2006. The pH of the digestive vacuole of Plasmodium falciparum is not associated with chloroquine resistance. $\mathrm{J}$. Cell Sci. 119, 1016-1025.

Hunt, P., Cravo, P.V.L., Donleavy, P., Carlton, J.M., Walliker, D., 2004. Chloroquine resistance in Plasmodium chabaudi: are chloroquineresistance transporter $(c r t)$ and multi-drug resistance $(m d r l)$ orthologues involved? Mol. Biochem. Parasitol. 133, 27-35.

Jacobs, G.H., Oduola, A.M.J., Kyle, D.E., Milhous, W.K., Martin, S.K., Aikawa, M., 1988. Ultrastructural study of the effects of chloroquine and verapamil on Plasmodium falciparum. Am. J. Trop. Med. Hyg. 39, 15-20.

Johnson, D.J., Fidock, D.A., Mungthin, M., Lakshmanan, V., Sidhu, A.B., Bray, P.G., Ward, S.A., 2004. Evidence for a central role for PfCRT in conferring Plasmodium falciparum resistance to diverse antimalarial agents. Mol. Cell 15, 867-877.

Kalkanidis, M., Klonis, N., Tilley, L., Deady, L.W., 2002. Novel phenothiazine antimalarials: synthesis, antimalarial activity, and inhibition of the formation of beta-haematin. Biochem. Pharmacol. 63, 833-842.

Kalkanidis, M., Klonis, N., Tschan, S., Deady, L.W., Tilley, L., 2004. Synergistic interaction of a chloroquine metabolite with chloroquine against drug-resistant malaria parasites. Biochem. Pharmacol. 67, 1347-1353.

Keefe, D.L., Yee, Y.-G., Kates, R.E., 1981. Verapamil protein binding in patients and in normal subjects. Clin. Pharmacol. Ther. 29, 21-26.

Kirk, K., Saliba, K.J., 2001. Chloroquine resistance and the $\mathrm{pH}$ of the malaria parasite's digestive vacuole. Drug Resist. Update 4, 335-337.

Krogstad, D.J., Gluzman, I.Y., Herwaldt, B.L., Schlesinger, P.H., Wellems, T.E., 1992. Energy dependence of chloroquine accumulation and chloroquine efflux in Plasmodium falciparum. Biochem. Pharmacol. 43, 57-62.

Krogstad, D.J., Gluzman, I.Y., Kyle, D.E., Oduola, A.M.J., Martin, S.K., Milhous, W.K., Schlesinger, P.H., 1987. Efflux of chloroquine from Plasmodium falciparum: mechanism of chloroquine resistance. Science 238 , 1283-1285.

Krogstad, D.J., Schlesinger, P.H., Gluzman, I.Y., 1985. Antimalarials increase vesicle $\mathrm{pH}$ in Plasmodium falciparum. J. Cell Biol. 101, 2302-2309.

Kyle, D.E., Milhous, W.K., Rossan, R.N., 1993. Reversal of Plasmodium falciparum resistance to chloroquine in Panamanian Aotus monkeys. Am. J. Trop. Med. Hyg. 48, 126-133.

Kyle, D.E., Oduola, A.M.J., Martin, S.K., Milhous, W.K., 1990. Plasmodium falciparum: modulation by calcium antagonists of resistance to chloroquine, desethylchloroquine, quinine, and quinidine in vitro. Trans. $\mathrm{R}$. Soc. Trop. Med. Hyg. 84, 474-478.

Lakshmanan, V., Bray, P.G., Verdier-Pinard, D., Johnson, D.J., Horrocks, P., Muhle, R.A., Alakpa, G.E., Hughes, R.H., Ward, S.A., Krogstad, D.J., Sidhu, A.B.S., Fidock, D.A., 2005. A critical role for PfCRT K76T in Plasmodium falciparum verapamil-reversible chloroquine resistance. EMBO J. 24, 2294-2305.

Lehnert, M., De Giuli, R., Kunke, K., Emerson, S., Dalton, W.S., Salmon, S.E., 1996. Serum can inhibit reversal of multidrug resistance by chemosensitizers. Eur. J. Cancer 32A, 862-867.

Li, G.D., Qu, F.Y., Chen, X., Ni, C.R., 1993. A 54-kDa protein overexpressed by chloroquine-resistant Plasmodium berghei ANKA strain. Acta Pharm. Sin. 14, 9-12.

Lim, A.S.Y., Galatis, D., Cowman, A.F., 1996. Plasmodium falciparum: amplification and overexpression of pfmdr1 is not necessary for increased mefloquine resistance. Exp. Parasitol. 83, 295-303.

Lim, P., Chy, S., Ariey, F., Incardona, S., Chim, P., Sem, R., Denis, M.B., Hewitt, S., Hoyer, S., Socheat, D., Merecreau-Puijalon, O., Fandeur, T., 2003. pfcrt polymorphism and chloroquine resistance in Plasmodium falciparum strains isolated in Cambodia. Antimicr. Agents Chemother. 47, 87-94.

Madrid, P.B., Sherrill, J., Liou, A.P., Weisman, J.L., DeRisi, J.L., Guy, R.K., 2005. Synthesis of ring-substituted 4-aminoquinolines and evaluation of their antimalarial activities. Bioorg. Med. Chem. Lett. 15, 1015-1018.

Martin, R.E., Kirk, K., 2004. The malaria parasite's chloroquine resistance transporter is a member of the drug/metabolite transporter superfamily. Mol. Biol. Evol. 21, 1938-1949.

Martin, S.K., Oduola, A.M.J., Milhous, W.K., 1987. Reversal of chloroquine resistance in Plasmodium falciparum by verapamil. Science 235, 899-901.

Martiney, J.A., Cerami, A., Slater, A.F.G., 1995. Verapamil reversal of chloroquine resistance in the malaria parasite Plasmodium falciparum is specific for resistant parasites and independent of the weak base effect. J. Biol. Chem. 270, 22393-22398.

Mehlotra, R.K., Fujioka, H., Roepe, P.D., Janneh, O., Ursos, L.M.B., JacobsLorena, V., McNamara, D.T., Bockarie, M.J., Kazura, J.W., Kyle, D.E., 
Fidock, D.A., Zimmerman, P.A., 2001. Evolution of a unique Plasmodium falciparum chloroquine-resistance phenotype in association with pfcrt polymorphism in Papua New Guinea and South America. Proc. Natl. Acad. Sci. U.S.A. 98, 12689-12694.

Menezes, C.M.S., Kirchgatter, K., Di Santi, S.M., Savalli, C., Monteiro, F.G., Paula, G.A., Ferreira, E.I., 2002. In vitro chloroquine resistance modulation study on fresh isolates of Brazilian Plasmodium falciparum: intrinsic antimalarial activity of phenothiazine drugs. Mem. Inst. Oswaldo Cruz 97, 1033-1039.

Menezes, C.M.S., Kirchgatter, K., Di Santi, S.M., Savalli, C., Monteiro, F.G., Paula, G.A., Ferreira, E.I., 2003. In vitro evaluation of verapamil and other modulating agents in Brazilian chloroquine-resistant Plasmodium falciparum isolates. Rev. Soc. Bras. Med. Trop. 36, 5-9.

Miki, A., Tanabe, K., Nakayama, T., Kiryon, C., Ohsawa, K., 1992. Plasmodium chabaudi: association of reversal of chloroquine resistance with increased accumulation of chloroquine in resistant parasites. Exp. Parasitol. 74, 134-142.

Nagesha, H.S., Casey, G.J., Rieckmann, K.H., Fryauff, D.J., Laksana, B.S., Reeder, J.C., Maguire, J.D., Baird, J.K., 2003. New haplotypes of the Plasmodium falciparum chloroquine resistance transporter $(p f c r t)$ gene among chloroquine-resistant parasite isolates. Am. J. Trop. Med. Hyg. 68, 398-402.

Navarro, M., Pérez, H., Sánchez-Delgado, R.A., 1997. Toward a novel metal-based chemotherapy against tropical diseases. 3. Synthesis and antimalarial activity in vitro and in vivo of the new gold-chloroquine complex $\left[\mathrm{Au}\left(\mathrm{PPh}_{3}\right)(\mathrm{CQ})\right] \mathrm{PF}_{6}$. J. Med. Chem. 40, 1937-1939.

Ndifor, A.M., Howells, R.E., Bray, P.G., Ngu, J.L., Ward, S.A., 1993. Enhancement of drug susceptibility in Plasmodium falciparum in vitro and Plasmodium berghei in vivo by mixed-function oxidase inhibitors. Antimicr. Agents Chemother. 37, 1318-1323.

Nomura, T., Carlton, J.M., Baird, J.K., Del Portillo, H.A., Fryauff, D.J., Rathore, D., Fidock, D.A., Su, X.Z., Collins, W.E., McCutchan, T.F., Wootton, J.C., Wellems, T.E., 2001. Evidence for different mechanisms of chloroquine resistance in 2 Plasmodium species that cause human malaria. J. Infect. Dis. 183, 1653-1661.

Nzila, A., Mberu, E., Bray, P.G., Kokwaro, G., Winstanley, P., Marsh, K., Ward, S.A., 2003. Chemosensitization of Plasmodium falciparum by probenecid in vitro. Antimicr. Agents Chemother. 47, 2108-2112.

Oduola, A.M., Omitowoju, G.O., Gerena, L., Kyle, D.E., Milhous, W.K., Sowunmi, A., Salako, L.A., 1993. Reversal of mefloquine resistance with penfluridol in isolates of Plasmodium falciparum from south-west Nigeria. Trans R. Soc. Trop. Med. Hyg. 87, 81-83.

Oduola, A.M.J., Sowunmi, A., Milhous, W.K., Brewer, T.G., Kyle, D.E., Gerena, L., Rossan, R.N., Salako, L.A., Schuster, B.G., 1998. In vitro and in vivo reversal of chloroquine resistance in Plasmodium falciparum with promethazine. Am. J. Trop. Med. Hyg. 58, 625-629.

O’Neill, P.M., Mukhtar, A., Stocks, P.A., Randle, L.E., Hindley, S., Ward, S.A., Storr, R.C., Bickley, J.F., O’Neil, I.A., Maggs, J.L., Hughes, R.H., Winstanley, P.A., Bray, P.G., Park, B.K., 2003. Isoquine and related amodiaquine analogues: a new generation of improved 4-aminoquinoline antimalarials. J. Med. Chem. 46, 4933-4945.

Osa, Y., Kobayashi, S., Sato, Y., Suzuki, Y., Takino, K., Takeuchi, T., Miyata, Y., Sakaguchi, M., Takayanagi, H., 2003. Structural properties of dibenzosuberanylpiperazine derivatives for efficient reversal of chloroquine resistance in Plasmodium chabaudi. J. Med. Chem. 46, 1948-1956.

Peters, W., Ekong, R., Robinson, B.L., Warhurst, D.C., Pan, X.Q., 1990. The chemotherapy of rodent malaria. XLV. Reversal of chloroquine resistance in rodent and human Plasmodium by antihistaminic agents. Ann. Trop. Med. Parasitol. 84, 541-551.

Peters, W., Robinson, B.L., 1991. The chemotherapy of rodent malaria. XLVI. Reversal of mefloquine resistance in rodent Plasmodium. Ann. Trop. Med. Parasitol. 85, 5-10.

Pouliot, J.F., L'Heureux, F., Liu, Z., Prichard, R.K., Georges, E., 1997. Reversal of P-glycoprotein-associated multidrug resistance by avermectin. Biochem. Pharmacol. 53, 17-25.

Rasonaivo, P., Ratsimamanga-Urverg, R., Milijaona, R., Rafatro, H., RakotoRatsimamanga, A., Galeffi, C., Nicoletti, M., 1994. In vitro and in vivo chloroquine-potentiating action of Strychnos myrtoides alkaloids against chloroquine-resistant strains of Plasmodium malaria. Planta Med. 60, 13-16.

Reed, M.B., Saliba, K.J., Caruana, S.R., Kirk, K., Cowman, A.F., 2000. Pgh1 modulates sensitivity and resistance to multiple antimalarials in Plasmodium falciparum. Nature 403, 906-909.

Ridley, R.G., Hofheinz, W., Matile, H., Jaquet, C., Dorn, A., Masciadri, R., Jolidon, S., Richter, W.F., Guenzi, A., Girometta, M.A., Urwyler, H., Huber, W., Thaithong, S., Peters, W., 1996. 4-Aminoquinoline analogues of chloroquine with shortened side-chains retain activity against chloroquine resistant Plasmodium falciparum. Antimicr. Agents Chemother. 40, 1846-1854.

Ridley, R.G., Hudson, A.T., 1998. Quinoline antimalarials. Exp. Opin. Ther. Patents 8, 121-136.

Rogan, A.M., Hamilton, T.C., Young, R.C., Klecker, R.W., Ozols, R.F., 1984. Reversal of adriamycin resistance by verapamil in human ovarian cancer. Science 224, 994-996.

Rubio, J.P., Cowman, A.F., 1994. Plasmodium falciparum: the pfmdr2 protein is not overexpressed in chloroquine-resistant isolates of the malaria parasite. Exp. Parasitol. 79, 137-147.

Sa, J.M., Nomura, T., Neves, J.D., Baird, J.K., Wellems, T.E., del Portillo, H.A., 2005. Plasmodium vivax: allele variants of the $m d r 1$ gene do not associate with chloroquine resistance among isolates from Brazil, Papua, and monkey-adapted strains. Exp. Parasitol. 109, 256-259.

Sachs, J., Malaney, P., 2002. The economic and social burden of malaria. Nature 415, 680-685.

Sanchez, C.P., McLean, J.E., Rohrbach, P., Fidock, D.A., Stein, W., Lanzer, M., 2005. Evidence for a pfcrt-associated chloroquine efflux system in the human malarial parasite Plasmodium falciparum. Biochemistry 44, 9862-9870

Sanchez, C.P., McLean, J.E., Stein, W., Lanzer, M., 2004. Evidence for a substrate specific and inhibitable drug efflux system in chloroquine resistant Plasmodium falciparum strains. Biochemistry 43, 1636516373.

Sanchez, C.P., Stein, W., Lanzer, M., 2003. Trans stimulation provides evidence for a drug efflux carrier as the mechanism of chloroquine resistance in Plasmodium falciparum. Biochemistry 42, 9383-9394.

Sidhu, A.B.S., Verdier-Pinard, D., Fidock, D.A., 2002. Chloroquine resistance in Plasmodium falciparum malaria parasites conferred by pfcrt mutations. Science 298, 210-213.

Singh, N., Puri, S.K., 2000. Interaction between chloroquine and diverse pharmacological agents in chloroquine resistant Plasmodium yoelii nigeriensis. Acta Trop. 77, 185-193.

Sowunmi, A., Oduola, A.M.J., 1997. Comparative efficacy of chloroquine/chlorpheniramine combination and mefloquine for the treatment of chloroquine-resistant Plasmodium falciparum malaria in Nigerian children. Trans R. Soc. Trop. Med. Hyg. 91, 689-693.

Sullivan, D.J., 2002. Theories on malarial pigment formation and quinoline action. Int. J. Parasitol. 32, 1645-1653.

Tanabe, K., Kato, M., Izumo, A., Hagiwara, A., Doi, S., 1990. Plasmodium chabaudi: in vivo effects of calcium antagonists on chloroquine-resistant and chloroquine-sensitive parasites. Exp. Parasitol. 70, 419-426.

Taylor, D., Walden, J.C., Robins, A.H., Smith, P.J., 2000. Role of the neurotransmitter re-uptake-blocking activity of antidepressants in reversing chloroquine resistance in vitro in Plasmodium falciparum. Antimicr. Agents Chemother. 44, 2689-2692.

Thomas, S.M., Ndir, O., Dieng, T., Mboup, S., Wypij, D., Maguire, J.H., Wirth, D.F., 2002. In vitro chloroquine susceptibility and PCR analysis of pfcrt and pfmdrl polymorphisms in Plasmodium falciparum isolates from Senegal. Am. J. Trop. Med. Hyg. 66, 474-480.

Tran, C.V., Saier, M.H., 2004. The principal chloroquine resistance protein of Plasmodium falciparum is a member of the drug/metabolite transporter superfamily. Microbiology 150, 1-3.

Ursos, L.M.B., Dzekunov, S.M., Roepe, P.D., 2000. The effects of chloroquine and verapamil on digestive vacuolar $\mathrm{pH}$ of $P$. falciparum either sensitive or resistant to chloroquine. Mol. Biochem. Parasitol. 110, 125-134. 
Van Schalkwyk, D.A., Walden, J.C., Smith, P.J., 2001. Reversal of chloroquine resistance in Plasmodium falciparum using combinations of chemosensitizers. Antimicr. Agents Chemother. 45, 3171-3174.

Waller, K.L., Muhle, R.A., Ursos, L.M.B., Horrocks, P., Verdier-Pinard, D., Sidhu, A.B.S., Fujioka, H., Roepe, P.D., Fidock, D.A., 2003. Chloroquine resistance modulated in vitro by expression levels of the Plasmodium falciparum chloroquine resistance transporter (PfCRT). J. Biol. Chem. 278, 33593-33601.

Warhurst, D.C., 2003b. Polymorphism in the Plasmodium falciparum chloroquine-resistance transporter protein links verapamil enhancement of chloroquine sensitivity with the clinical efficacy of amodiaquine. Malaria J. 2, 31-43.

Warhurst, D.C., Craig, J.C., Adagu, I.S., Meyer, D.J., Lee, S.Y., 2003a. The relationship of physico-chemical properties and structure to the differential antiplasmodial activity of the cinchona alkaloids. Malaria J. 2, 26.

Warsame, M., Wernsdorfer, W.H., Bjorkman, A., 1992. Lack of effect of desipramine on the response to chloroquine of patients with chloroquineresistant falciparum malaria. Trans R. Soc. Trop. Med. Hyg. 86, 235-236.

Watt, G., Long, G.W., Grogl, M., Martin, S.K., 1990. Reversal of drugresistant falciparum malaria by calcium antagonists: potential for host cell toxicity. Trans R. Soc. Trop. Med. Hyg. 84, 187-190.

Wellems, T.E., Panton, L.J., Gluzman, I.Y., do Rosario, V.E., Gwadz, R.W., Walker-Jonah, A., Krogstad, D.J., 1990. Chloroquine resistance not linked to $m d r$-like genes in a Plasmodium falciparum cross. Nature 345, 253-255.

WHO Expert Committee on Malaria, 2000. Technical Report Series. Twentieth Report. Geneva, World Health Organization: 1-83.
Williams, H.L., Johnson, D.J., Okoye, V.C., Martin, S.K., 1992. Treatment of chloroquine-resistant malaria in monkeys with a drug combination that reverses resistance in vitro. Ann. Trop. Med. Parasitol. 86, 467-473.

Wilson, C.M., Serrano, A.E., Wasley, A., Bogenschutz, M.P., Shankar, A.H., Wirth, D.F., 1989. Amplification of a gene related to mammalian mdr genes in drug-resistant Plasmodium falciparum. Science $244,1184-1186$

Ye, Z.G., Van Dyke, K., 1988. Reversal of chloroquine resistance in falciparum malaria independent of calcium channels. Biochem. Biophys. Res. Commun. 155, 476-481.

Ye, Z.G., Van Dyke, K., Castranova, V., 1989. The potentiating action of tetrandrine in combination with chloroquine or qinghaosu against chloroquine-sensitive and resistant falciparum malaria. Biochem. Biophys. Res. Commun. 165, 758-765.

Zacherl, J., Hamilton, G., Thalhammer, T., Riegler, M., Cosentini, E.P., Ellinger, A., Bischof, G., Schweitzer, M., Teleky, B., Koperna, T., Wenzl, E., 1994. Inhibition of P-glycoprotein-mediated vinblastine transport across HCT-8 intestinal carcinoma monolayers by verapamil, cyclosporine A and SDZ PSC 833 in dependence on extracellular $\mathrm{pH}$ Cancer Chemother. Pharmacol. 34, 125-132.

Zhang, H., Paguio, M., Roepe, P.D., 2004. The antimalarial drug resistance protein Plasmodium falciparum chloroquine resistance transporter binds chloroquine. Biochemistry 43, 8290-8296.

Ziegler, J., Linck, R., Wright, D.W., 2001. Heme aggregation inhibitors: antimalarial drugs targeting an essential biomineralization process. Curr. Med. Chem. 8, 171-189. 